\title{
The era of the Heart Doctor
}

\author{
Devendra Saksena ${ }^{1}$ (D)
}

Received: 7 April 2017 / Accepted: 11 April 2017 / Published online: 31 May 2017

(C) Indian Association of Cardiovascular-Thoracic Surgeons 2017

When I started cardiac surgery training in the early 1960 s, we had to deal with the whole gamut of thoracic, cardiac, and vascular surgery from congenital heart disease to congenital tracheo-esophageal fistula. We had to do all types of thoracic surgery like lung cancer, hiatus hernia, esophageal cancers and strictures, and portal hypertension. The entire vascular surgery domain from the carotid to the most distal tibial disease was under our control. We also had to participate in kidney transplant and major surgeries. In other words, all major surgeries were under our domain. We also had to do angiography, i.e., translumbar, coronary, and arch studies. If we got time from all this, we had to put in permanent pacemakers at night. At that time, the heart surgeon was "king" and most of the chairmen of surgery in the US medical schools were cardiovascular surgeons. Gradually, we seceded territory, one after the other, till in the 1980 s when we were doing only valve surgery and coronary bypass surgery. We were so busy doing coronary surgery that we forgot that there is a world outside coronary revascularization. In the late 1980s and early 1990s, most of our younger cardiac surgeons became a one operation surgeon, i.e., coronary bypass.

As we were hit by the tsunami of angioplasty, we thought it was a minor aberration and would go away soon; not realizing the tenacity and the amount of money the industry was spending in developing angioplasty. We soon realized in the last decade that cardiac surgery was a sinking ship and had to be retrieved. Soon, aortic valve, atrial fibrillation surgery, left atrial ablation, and mitral valve repair were being invaded by the cardiologists. The endovascular physicians were taking away large volume of the vascular work. We were finally waking up and venturing into minimally invasive surgery. In order to compete with the cardiology colleagues, we should realize that regardless of the size of incision, we can never be as minimal as our cardiology colleagues with a needle prick. Now, it is clear that we cannot lick them, so we should join them and develop catheter skills so that we can contribute to the well being of the patient with heart disease. We should talk to them rather than talk at them. Since we, the cardiac surgeons, have detailed knowledge of the anatomy and physiology of the heart, we should join our cardiology colleagues so that we can jointly and efficiently treat heart disease in the best interest of the patient.

The time has come that the cardiac surgeon and the cardiologist have to work as a team to provide maximum help to the patients as "Heart Doctors".

Devendra Saksena

devsaksena@gmail.com

1 Cardiovascular \& Thoracic Surgery, Bombay Hospital Institute of Medical Sciences, Room no. 130, MRC, Bombay Hospital, Mumbai, Maharashtra 400020, India 